\title{
Obstetric and neonatal outcomes in women with pregnancy associated cancer: a population-based study in Lombardy, Northern Italy
}

Giovanna Esposito ${ }^{1,2,3}$, Matteo Franchi ${ }^{1,2}$, Michela Dalmartello ${ }^{3}$, Giovanna Scarfone ${ }^{4}$, Eva Negri ${ }^{3}$, Fabio Parazzini ${ }^{3,4^{*}}$ (D), Carlo La Vecchia ${ }^{3}$ and Giovanni Corrao ${ }^{1,2}$

\begin{abstract}
Background: Pregnancy associated cancer (PAC) may lead to adverse obstetric and neonatal outcomes. This study aims to assess the association between PACs and adverse perinatal outcomes [i.e. labor induction, iatrogenic delivery, preterm birth, small for gestational age (SGA) newborn, low Apgar score, major malformations, perinatal mortality] in Lombardy, Northern Italy.

Methods: This population-based historic cohort study used the certificate of delivery assistance and the regional healthcare utilization databases of Lombardy Region to identify beneficiaries of National Health Service who delivered between 2008 and 2017. PACs were defined through oncological ICD-9-CM codes reported in the hospital discharge forms. Each woman with PAC was matched to four women randomly selected from those cancer-free (1:4). Log-binomial regression models were fitted to estimate crude and adjusted prevalence ratio (aPR) and the corresponding 95\% confidence interval $(\mathrm{Cl})$ of each perinatal outcome among PAC and cancer-free women.

Results: Out of the 657,968 deliveries, 831 PACs were identified (1.26 per 1000). PAC diagnosed during pregnancy was positively associated with labor induction or planned delivery ( $\mathrm{PPR}=1.80,95 \% \mathrm{Cl}$ : 1.57-2.07), cesarean section (aPR=1.78, 95\% Cl: 1.49-2.11) and premature birth (aPR=6.34, 95\% Cl: 4.59-8.75). No association with obstetric outcomes was found among PAC diagnosed in the post-pregnancy. No association of PAC, neither during pregnancy nor in post-pregnancy was found for SGA (aPR=0.71,95\% Cl: $0.36-1.35$ and aPR=1.04, 95\% Cl: 0.78-1.39, respectively), but newborn among PAC women had a lower birth weight ( $p$-value< 0.001 ). Newborns of women with PAC diagnosed during pregnancy had a higher risk of borderline significance of a low Apgar score ( $\mathrm{APR}=2.65$, 95\% Cl: 0.96-7.33) as compared to cancer-free women.

\footnotetext{
*Correspondence: fabio.parazzini@unimi.it

${ }^{3}$ Department of Clinical Sciences and Community Health, University of Milan, 20122 Milan, Italy

${ }^{4}$ Department of Obstetrics, Gynecology and Neonatology, University of Milan, Fondazione IRCCS Ca' Granda Ospedale Maggiore Policlinico, 20122 Milan, Italy

Full list of author information is available at the end of the article
}

C C The Author(s). 2021 Open Access This article is licensed under a Creative Commons Attribution 4.0 International License, which permits use, sharing, adaptation, distribution and reproduction in any medium or format, as long as you give appropriate credit to the original author(s) and the source, provide a link to the Creative Commons licence, and indicate if changes were made. The images or other third party material in this article are included in the article's Creative Commons licence, unless indicated otherwise in a credit line to the material. If material is not included in the article's Creative Commons licence and your intended use is not permitted by statutory regulation or exceeds the permitted use, you will need to obtain permission directly from the copyright holder. To view a copy of this licence, visit http://creativecommons.org/licenses/by/4.0/. The Creative Commons Public Domain Dedication waiver (http://creativecommons.org/publicdomain/zero/1.0/) applies to the data made available in this article, unless otherwise stated in a credit line to the data. 
(Continued from previous page)

Conclusion: PAC, especially when diagnosed during pregnancy, is associated with iatrogenic preterm delivery, compromising some neonatal heath indicators.

Keywords: Cancer, Pregnancy, Neonatal outcome, Pregnancy outcome, Population-based

\section{Background}

Pregnancy associated cancer (PAC) is defined as cancer diagnosed during pregnancy or within 12 months following childbirth or abortion [1-5]. Its prevalence is reported to be about $1 / 1000$ pregnancies [6]. A diagnosis of PAC may affect women's treatment and survival, due to the challenge of targeting both maternal and fetal health. In addition, PAC, especially when diagnosed during pregnancy, may lead to adverse obstetric and neonatal outcomes [7]. About 15\% of women with a diagnosis of PAC experience obstetric complications [i.e. premature membrane rupture prior to week 37 (PPROM), preeclampsia, blood loss and intrauterine growth restriction (IUGR)]. Nevertheless, the risk does not appear to be significantly higher than the general population [8]. Compared to healthy women, the risk of spontaneous preterm birth is also not significantly higher [9]. In contrast, medically induced labor or elective cesarean section are more frequently performed, due to the need of an early pregnancy termination in order to start surgical or pharmacological treatment [8-10]. Nevertheless, most of these results come from clinical series based on a specific context. For example, a recent observational cohort study [11] of women diagnosed with cancer in pregnancy aims to investigate the use of chemotherapy during the first trimester. Initiating chemotherapy in the first period of pregnancy significantly increase risk of IUGR [Odds Ratio $(\mathrm{OR})=3.00$ ], of congenital anomalies $(\mathrm{OR}=3.9)$ and of preterm birth $(\mathrm{OR}=2.3)$. Limited evidence has been published on the perinatal outcomes in women with PAC in populationbased studies [6].

In order to add further evidence on obstetric and neonatal outcomes in women with and without PAC, a large retrospective population-based cohort study, including women who delivered between 2008 and 2017 in Lombardy, Northern Italy, was carried out.

\section{Methods}

\section{Data sources}

Data were retrieved from the regional healthcare utilization (HCU) databases of Lombardy Region, the most populated region in Northern Italy, accounting for about 10 million inhabitants ( $17 \%$ of the national population). All Italian citizens have equal access to health care services as part of the National Health Service (NHS), and in Lombardy this has been associated with an automated system of databases to collect a variety of information on residents who receive NHS assistance (NHS beneficiaries), diagnoses and procedures of inpatients of public or private hospitals (coded according to the ICD-CM-9 codes), outpatient drug prescriptions (coded according to the Anatomical Therapeutic Chemical (ATC) Classification System), specialist visits and diagnostic examinations reimbursable by the NHS. In addition, a database reporting the Certificates of Delivery Assistance (i.e., the so called CeDAP registry) providing detailed information on the mother's socioeconomic traits, as well as detailed information regarding course of pregnancy, labor (e.g. induction), delivery (e.g. mode and timing), health of newborn (e.g. birth weight, Apgar score, presence of congenital malformation or major defect) and causes of perinatal mortality where applicable. A deterministic record linkage between databases through a unique identification code systematically used for all databases allows the identification of large and unselected birth cohorts and the possibility of establishing relevant traits and care pathways of mothers and newborns [12]. To preserve privacy, each identification code is automatically anonymized and the inverse process is allowed only to the Regional Health Authority on request from judicial authorities. Diagnostic, therapeutic and procedural codes used for the current study are given in Supplementary material (Table S1).

As previously underlines the analysis are based on anonymized data: no permission by Ethic Committees is necessary to collect and analyze these data.

\section{Study cohort and PAC definition}

All the deliveries in Lombardy between 1st January 2008 and 30th June 2017 from women who (i) were beneficiaries of NHS and resident in Lombardy (at least since three years before the conception date and one year after the delivery date), (ii) were aged 12 to 55 years at delivery, (iii) had 22 to 42 weeks of gestation, and (iv) did not have an ICD-9 code related to cancer in the three years prior to the conception date were identified from CeDAP database. Among these, we excluded deliveries of newborns with very low birth weight (i.e., less than $400 \mathrm{~g}$ ), deliveries with missing values on Apgar score, birth weight and vitality status, deliveries which did not match to a hospital ICD-9 code related to childbirth, and those in which the infant could not be linked to the mother because of a missing identification code. 
Information on cancer diagnosis was obtained from the inpatient database. Accordingly, women with PAC were defined as those having an ICD-9 code of cancer, either in the main or in secondary diagnoses, during the period from conception to delivery (i.e., during pregnancy) or during the following 12 months (i.e. postpregnancy). Cancer cases reported as secondary diagnosis, for which the main diagnosis was unrelated to cancer, were excluded.

Each woman with PAC was matched to four women randomly selected from those cancer-free, having the same maternal age and year of delivery. PAC and cancer-free women were also compared for sociodemographic characteristics (including nationality, marital status, education and employment), type of conception (i.e. spontaneous or assisted), multiple births, parity and previous history of type 2 diabetes and hypertension (detected in the three years before the date of conception).

\section{Outcomes of interest}

Information on pregnancy, delivery and newborn were retrieved from the CeDAP database. Adverse obstetric outcomes included type of labor (induced or no labor due to elective cesarean section vs spontaneous), mode of delivery (cesarean section vs vaginal or instrumental) and timing of delivery (preterm, i.e. 37 gestation weeks or less, vs at term [13]). Adverse neonatal outcomes included small for gestational age (SGA) newborn, low Apgar score at $5 \mathrm{~min}$ (7 or less [14]), perinatal death and major malformations diagnosed before discharge of the newborn. SGA was defined as having a birth weight below the 10th percentile for gestational age, according to the sex-specific Italian reference curve for normal fetal growth [15].

\section{Statistical analyses}

Descriptive statistics were used to summarize characteristics of PAC and cancer-free women. Differences on categorical variables between the two groups were tested by using absolute standardized differences. Numerical variables were compared between two groups by using the t-test for independent samples.

The overall prevalence of PAC in our study cohort was calculated by dividing the observed number of PAC by the total number of deliveries. Prevalence were further stratified by cancer site. Log-binomial regression models were fitted to estimate the prevalence ratio (PR) and the corresponding 95\% confidence interval (CI) of each perinatal outcome among PAC and cancer-free women. Other than the crude PR, adjusted PR (aPR) were also estimated, with allowance for sociodemographic characteristics (nationality, marital status, education and employment), type of conception (i.e. spontaneous of assisted), multiple births, parity and previous history of type 2 diabetes and hypertension. Given the low number of observed cases for some of the outcomes considered, we could not adjust the model for all the aforementioned covariates. Thus, we first used a multivariate logistic regression model for estimating the probability of having a diagnosis of PAC, given the characteristics reported below, and then we used this probability as adjustment covariate in the log-binomial regression model [16]. Moreover, because of the potential correlation of women contributing to more than one birth during the considered period, the models were fitted using generalized estimating equations (GEE) for correlated observations with a log link [17]. Finally, because socio-demographic characteristics were missing for some women $(<3 \%)$, multiple imputations were applied by using the fully conditional specification (FCS) method, imputing 20 datasets [18, 19].

All the analyses were performed among strata of timing of PAC diagnosis (i.e. during pregnancy and postpregnancy). The frequencies of perinatal outcomes were also reported separately for the three most common cancer sites (i.e. breast, thyroid cancer and lymphoma). Chisquared test or Fisher's exact test was used to evaluate differences between cancer sites.

All analyses were performed using the Statistical Analysis System Software (version 9.4; SAS Institute, Cary, NC, USA). Statistical significance was set at the 0.05 level. All $p$-values were two-sided.

\section{Results}

\section{Study population}

During the study period, 795,651 births were identified. Among these, we excluded deliveries from mothers who were not resident in Lombardy $(N=125$, 387 ), who were aged less than 12 or more than 55 years at delivery $(N=430)$, who had less than 22 or more than 42 weeks of gestation $(N=1547)$ and who had a previous history of cancer $(N=1687)$. In addition, we excluded 625 deliveries with missing values on Apgar score, 483 on vitality status and 77 on birth weight, 7408 deliveries who did not match to a hospital ICD-9 code related to childbirth and 39 deliveries with infant missing identification code. Thus, the final cohort included 657,968 deliveries.

Overall, 853 women with PAC were observed. After excluding 24 cases with non-cancer related primary diagnosis (likely not incident cases), 831 women with PAC were selected, corresponding to 1.26 cases per 1000 deliveries. Those were matched to 3324 cancer-free women. Among PAC, 30 (3.6\%), 53 (6.4\%) and 103 (12.4\%) were diagnosed, respectively, during the first, the second and third trimester of pregnancy, while 645 
Table 1 Maternal characteristics in the matched cohort of 831 women with pregnancy associated cancer (PAC) and 3324 cancerfree women. Lombardy, Italy. 2008-2017

\begin{tabular}{|c|c|c|c|}
\hline & $\begin{array}{l}\text { Pregnancy associated cancer women } \\
N=831\end{array}$ & $\begin{array}{l}\text { Cancer-free women } \\
N=3324\end{array}$ & Standardized difference (absolute) \\
\hline & $N(\%)$ & $N(\%)$ & \\
\hline \multicolumn{4}{|l|}{ Maternal Age $\left(\right.$ Year) ${ }^{a}$} \\
\hline$<30$ & $107(12.9)$ & $428(12.9)$ & Matching variable \\
\hline $30-34$ & $260(31.3)$ & $1040(31.3)$ & \\
\hline $35-40$ & $379(45.6)$ & $1516(45.6)$ & \\
\hline$>40$ & $85(10.2)$ & $340(10.2)$ & \\
\hline Mean (SD) & $34.8(4.6)$ & $34.8(4.6)$ & \\
\hline \multicolumn{4}{|l|}{ Calendar Year at Birth ${ }^{\mathrm{a}, \mathrm{b}}$} \\
\hline 2008 & $84(10.1)$ & $336(10.1)$ & Matching variable \\
\hline 2009 & $75(9.0)$ & $300(9.0)$ & \\
\hline 2010 & $100(12.0)$ & $400(12.0)$ & \\
\hline 2011 & $98(11.8)$ & $392(11.8)$ & \\
\hline 2012 & $83(10.0)$ & $332(10.0)$ & \\
\hline 2013 & $82(9.9)$ & $328(9.9)$ & \\
\hline 2014 & $87(10.5)$ & $348(10.5)$ & \\
\hline 2015 & $84(10.1)$ & $336(10.1)$ & \\
\hline 2016 & $86(10.4)$ & $344(10.4)$ & \\
\hline 2017 & $52(6.3)$ & $208(6.3)$ & \\
\hline \multicolumn{4}{|l|}{ Nationality } \\
\hline Italian & $725(87.2)$ & $2808(84.5)$ & 0.078 \\
\hline Foreign & $106(12.8)$ & $516(15.5)$ & -0.078 \\
\hline \multicolumn{4}{|l|}{ Marital Status } \\
\hline Married & $575(69.2)$ & $2272(68.4)$ & 0.018 \\
\hline Not Married & $234(28.2)$ & $981(29.5)$ & -0.030 \\
\hline Missing & $22(2.6)$ & $71(2.1)$ & 0.033 \\
\hline \multicolumn{4}{|l|}{ Education } \\
\hline Middle School or lower & $163(19.6)$ & $711(21.4)$ & -0.044 \\
\hline High School & $382(46.0)$ & $1471(44.3)$ & 0.034 \\
\hline University or upper & $282(33.9)$ & 1118 (33.6) & 0.006 \\
\hline Missing & $4(0.5)$ & $24(0.7)$ & -0.031 \\
\hline \multicolumn{4}{|l|}{ Employment } \\
\hline Employed & $665(80.0)$ & $2616(78.7)$ & 0.033 \\
\hline Not employed & $165(19.9)$ & $708(21.3)$ & -0.036 \\
\hline Missing & $1(0.1)$ & $0(0.0)$ & 0.049 \\
\hline \multicolumn{4}{|l|}{ Type of conception } \\
\hline Spontaneous & $799(96.1)$ & $3180(95.7)$ & 0.024 \\
\hline Assisted & $29(3.5)$ & $132(4.0)$ & -0.025 \\
\hline Missing & $3(0.4)$ & $12(0.4)$ & 0.0 \\
\hline \multicolumn{4}{|l|}{ History of diabetes } \\
\hline No & $822(98.9)$ & 3307 (99.5) & -0.067 \\
\hline Yes & $9(1.1)$ & $17(0.5)$ & 0.067 \\
\hline \multicolumn{4}{|l|}{ History of hypertension } \\
\hline No & $800(96.3)$ & $3233(97.3)$ & -0.057 \\
\hline
\end{tabular}


Table 1 Maternal characteristics in the matched cohort of 831 women with pregnancy associated cancer (PAC) and 3324 cancerfree women. Lombardy, Italy. 2008-2017 (Continued)

\begin{tabular}{llll}
\hline & $\begin{array}{l}\text { Pregnancy associated cancer women } \\
\mathbf{N}=\mathbf{8 3 1}\end{array}$ & $\begin{array}{l}\text { Cancer-free women } \\
\boldsymbol{N}=\mathbf{3 3 2 4}\end{array}$ & Standardized difference (absolute) \\
\hline Yes & $31(3.7)$ & $91(2.7)$ & 0.057
\end{tabular}

${ }^{a}$ Matching variable

${ }^{\mathrm{b}}$ The study cohort includes all women who delivered from 01/01/2008 to 30/06/2017

(77.6\%) were diagnosed during the year post-pregnancy. The most common cancer site was breast $(N=259$, corresponding to 39.3 cases per 100,000 births), followed by thyroid ( $N=138$, corresponding to 21.0 cases per 100,000 births) and lymphoma ( $N=103$, corresponding to 15.3 cases per 100,000 births) (See Supplementary Table S2 for a detailed list of all cancer sites).

Maternal characteristics between PAC and cancer-free women are shown in Table 1. Average maternal age was 34.8 years. No differences were observed on nationality, marital status, education and employment, type of conception and history of diabetes and hypertension. Maternal characteristics of the unmatched initial cohort are reported in Supplementary Table S3.

\section{Obstetric outcomes}

PAC diagnosed during pregnancy were positively associated with induction of labor or planning of delivery $(\mathrm{aPR}=1.80,95 \% \mathrm{CI}: 1.57-2.07)$, cesarean section $(\mathrm{aPR}=$ $1.78,1.49-2.11)$ and premature birth $(\mathrm{aPR}=6.34,4.59$ $8.75)$. In particular, we observed a slightly higher association between PAC diagnosed during pregnancy and preterm births fewer the 32th week, rather than those between the 28th and the 32th week and those between the 32th and the 34th week; corresponding aPR are 8.41 (2.74-25.83), $8.07(3.31-19.64)$ and 7.26 (5.00-10.76) (data not shown). No association with obstetric outcomes was found among PAC diagnosed in the postpregnancy. Corresponding aPR are 1.08 (0.98-1.20), 1.03 (0.91-1.17) and 1.18 (0.90-1.55) (Table 2).

Among preterm births, a significantly higher proportion of induced deliveries or elective cesarean sections emerged among PAC women $(70.3 \%$ vs $46.4 \%$, $p$-value< 0.001, data not shown).

\section{Neonatal outcomes}

No associations between PAC and SGA newborns was observed, neither for cancer diagnosed during pregnancy $(\mathrm{aPR}=0.71,0.36-1.35)$ nor for those diagnosed postpregnancy $(\mathrm{aPR}=1.04,0.78-1.39)$ (Table 3). Also comparing frequencies of SGA among women with cancer diagnosed during pregnancy and women with cancer diagnosed post-pregnancy we did not observe differences $(p$-value $=0.2325)$. Newborns of women with PAC diagnosed during pregnancy had a higher risk of borderline significance of a low Apgar score $(\mathrm{aPR}=2.65,0.96-7.33)$ as compared to cancer-free women, whereas no difference was found for women with PAC diagnosed postpregnancy $(\mathrm{aPR}=0.66,0.30-1.46)$ (Table 3$)$. A few cases of newborn malformations ( 0 among PAC and 3 among cancer-free women) and perinatal mortality (1 among PAC and 2 among cancer-free women) were observed. Newborns had a lower average birth weight among PAC women with respect to cancer-free women $(3109 \pm 588 \mathrm{~g}$

Table 2 Adverse obstetric outcomes among 831 women with pregnancy associated cancer (PAC) and 3324 matched cancer-free women. Lombardy, Italy. 2008-2017

\begin{tabular}{|c|c|c|c|c|c|c|c|c|c|}
\hline & \multicolumn{3}{|c|}{$\begin{array}{l}\text { Labor induction or planning of } \\
\text { delivery }{ }^{\text {a }} \text { (Induced or elective CS } \\
\text { Vs } \\
\text { Spontaneous) }\end{array}$} & \multicolumn{3}{|c|}{$\begin{array}{l}\text { Mode of delivery }{ }^{\text {b }} \text { (Emergency or } \\
\text { elective CS } \\
\text { Vs } \\
\text { vaginal or instrumental) }\end{array}$} & \multicolumn{3}{|c|}{$\begin{array}{l}\text { Timing of delivery (Very low, low, } \\
\text { moderate or late preterm }{ }^{c} \\
\text { Vs } \\
\text { at term) }\end{array}$} \\
\hline & $\begin{array}{l}\mathrm{N}(\%) \text { of } \\
\text { events }\end{array}$ & $\begin{array}{l}\text { PR }(95 \% \\
\text { Cl) }\end{array}$ & $\begin{array}{l}\text { aPR }(95 \% \\
\mathrm{Cl})\end{array}$ & $\begin{array}{l}\mathrm{N}(\%) \text { of } \\
\text { events }\end{array}$ & $\begin{array}{l}\text { PR }(95 \% \\
\mathrm{Cl})\end{array}$ & $\begin{array}{l}\text { aPR }(95 \% \\
\text { Cl) }\end{array}$ & $\begin{array}{l}\mathrm{N}(\%) \text { of } \\
\text { events }\end{array}$ & $\begin{array}{l}\text { PR }(95 \% \\
\text { Cl) }\end{array}$ & $\begin{array}{l}\text { aPR }(95 \% \\
\mathrm{Cl})\end{array}$ \\
\hline Cancer-free & $299(40.9)$ & $1^{d}$ & $1^{d}$ & $226(30.4)$ & $1^{d}$ & $1^{d}$ & $48(6.5)$ & $1^{d}$ & $1^{d}$ \\
\hline $\begin{array}{l}\text { PAC during } \\
\text { pregnancy }\end{array}$ & $139(76.0)$ & $\begin{array}{l}1.86(1.65- \\
2.10)\end{array}$ & $\begin{array}{l}1.80(1.57- \\
2.07)\end{array}$ & $100(54.0)$ & $\begin{array}{l}1.78(1.50- \\
2.11)\end{array}$ & $\begin{array}{l}1.78(1.49- \\
2.11)\end{array}$ & 77 (41.4) & $\begin{array}{l}6.42(4.65- \\
8.86)\end{array}$ & $\begin{array}{l}6.34(4.59- \\
8.75)\end{array}$ \\
\hline Cancer-free & $1027(40.3)$ & $1^{d}$ & $1^{d}$ & 807 (31.5) & $1^{d}$ & $1^{d}$ & $198(7.7)$ & $1^{d}$ & $1^{d}$ \\
\hline $\begin{array}{l}\text { PAC post- } \\
\text { pregnancy }\end{array}$ & $283(44.2)$ & $\begin{array}{l}1.10(0.99- \\
1.21)\end{array}$ & $\begin{array}{l}1.08(0.98- \\
1.20)\end{array}$ & 209 (32.6) & $\begin{array}{l}1.03(0.91- \\
1.15)\end{array}$ & $\begin{array}{l}1.03(0.91- \\
1.17)\end{array}$ & $61(9.5)$ & $\begin{array}{l}1.23(0.94- \\
1.62)\end{array}$ & $\begin{array}{l}1.18(0.90- \\
1.55)\end{array}$ \\
\hline
\end{tabular}

PR Prevalence ratio; aPR adjusted Prevalence Ratio; CI Confidence Intervals; CS Cesarean Section; PAC Pregnancy Associated Cancer

${ }^{a}$ Were excluded from the analysis 8 and 46 observations with missing values among PAC and non PAC women, respectively

${ }^{b}$ Were excluded from the analysis 4 and 16 observations with missing values among PAC and non PAC women, respectively

'Very low preterm birth: before 28th week, low preterm birth: between the 28th and the 32th week, moderate preterm birth: between the 32th and the 34th week, late preterm birth: between the 34th and the 37th week

${ }^{\mathrm{d}}$ Reference category 
Table 3 Adverse neonatal outcomes among 831 women with pregnancy associated cancer (PAC) and 3324 matched cancer-free women. Lombardy, Italy. 2008-2017

\begin{tabular}{|c|c|c|c|c|c|c|c|c|c|c|c|c|}
\hline & \multicolumn{3}{|c|}{$\begin{array}{l}\text { Small for gestational age } \\
\text { (Yes Vs No) }\end{array}$} & \multicolumn{3}{|c|}{$\begin{array}{l}\text { Apgar 5th Minute (Low Vs } \\
\text { Normal) }\end{array}$} & \multicolumn{3}{|c|}{ Malformations (Yes Vs No) } & \multicolumn{3}{|c|}{$\begin{array}{l}\text { Perinatal Mortality (Stillbirth } \\
\text { Vs Livebirth) }\end{array}$} \\
\hline & $\begin{array}{l}\mathrm{N}(\%) \\
\text { events }\end{array}$ & $\begin{array}{l}\text { PR }(95 \% \\
\text { Cl) }\end{array}$ & $\begin{array}{l}\text { aPR } \\
(95 \% \mathrm{Cl})\end{array}$ & $\begin{array}{l}N(\%) \\
\text { events }\end{array}$ & $\begin{array}{l}\text { PR }(95 \% \\
\text { Cl) }\end{array}$ & $\begin{array}{l}\text { aPR } \\
(95 \% \mathrm{Cl})\end{array}$ & $\begin{array}{l}\mathrm{N}(\%) \\
\text { events }\end{array}$ & $\begin{array}{l}\text { PR }(95 \% \\
\text { Cl) }\end{array}$ & $\begin{array}{l}\text { aPR }(95 \% \\
\text { Cl) }\end{array}$ & $\begin{array}{l}\mathrm{N}(\%) \\
\text { events }\end{array}$ & $\begin{array}{l}\text { PR }(95 \% \\
\text { Cl) }\end{array}$ & $\begin{array}{l}\text { aPR } \\
(95 \% \mathrm{Cl})\end{array}$ \\
\hline Cancer-free & $57(7.7)$ & $1^{\mathrm{a}}$ & $1^{a}$ & $9(1.2)$ & $1^{\mathrm{a}}$ & $1^{\mathrm{a}}$ & $1(0.1)$ & $1^{a}$ & $1^{a}$ & $4(0.5)$ & $1^{a}$ & $1^{\mathrm{a}}$ \\
\hline $\begin{array}{l}\text { PAC during } \\
\text { pregnancy }\end{array}$ & $10(5.4)$ & $\begin{array}{l}0.70 \\
(0.37- \\
1.35)\end{array}$ & $\begin{array}{l}0.71 \\
(0.36- \\
1.35)\end{array}$ & $6(3.2)$ & $\begin{array}{l}2.67 \\
(0.96- \\
7.40)\end{array}$ & $\begin{array}{l}2.65 \\
(0.96- \\
7.33)\end{array}$ & $0(0.0)$ & \multicolumn{2}{|c|}{ Not estimable } & $1(0.5)$ & $\begin{array}{l}1.00 \\
(0.11- \\
8.89)\end{array}$ & $\begin{array}{l}1.01 \\
(0.11- \\
8.29)\end{array}$ \\
\hline Cancer-free & $204(7.9)$ & $1^{\mathrm{a}}$ & $1^{\mathrm{a}}$ & $41(1.6)$ & $1^{\mathrm{a}}$ & $1^{\mathrm{a}}$ & $1(0.0)$ & $1^{\mathrm{a}}$ & $1^{\mathrm{a}}$ & $6(0.2)$ & $1^{\mathrm{a}}$ & $1^{\mathrm{a}}$ \\
\hline $\begin{array}{l}\text { PAC post- } \\
\text { pregnancy }\end{array}$ & $54(8.4)$ & $\begin{array}{l}1.06 \\
(0.79- \\
1.41)\end{array}$ & $\begin{array}{l}1.04 \\
(0.78- \\
1.39)\end{array}$ & $8(1.2)$ & $\begin{array}{l}0.78 \\
(0.37- \\
1.66)\end{array}$ & $\begin{array}{l}0.66 \\
(0.30- \\
1.46)\end{array}$ & $3(0.5)$ & $\begin{array}{l}12.00 \\
(1.2- \\
115.2)\end{array}$ & $\begin{array}{l}11.53 \\
(1.2- \\
111.5)\end{array}$ & $2(0.3)$ & $\begin{array}{l}1.33 \\
(0.27- \\
6.59)\end{array}$ & $\begin{array}{l}0.59 \\
(0.07- \\
4.94)\end{array}$ \\
\hline
\end{tabular}

PR Prevalence ratio; $a P R$ adjusted Prevalence Ratio; $C I$ Confidence Intervals

${ }^{\text {a }}$ Reference category

vs $3232 \pm 522 \mathrm{~g}, p$-value $<0.0001)$. Further, a lower average birth weight was observed among PAC diagnosed during pregnancy, with respect to PAC diagnosed after pregnancy $(2853 \pm 578 \mathrm{~g}$ vs $3183 \pm 570 \mathrm{~g}, p$-value $<0.0001)$.

Among women diagnosed with PAC during pregnancy we detected 27 (14.5\%) women exposed to chemotherapy. No association between adverse neonatal outcomes and exposure to chemotherapy was found, in particular for SGA newborns ( $p$-value $=0.6768)$ and low Apgar score to $5 \mathrm{~min}$ ( $\mathrm{p}$-value $=0.1835$ ). However, we observed that chemotherapy may affect the birth weight. The mean weight of birth among infants exposed to chemotherapy is lower if compared with those not exposed (respectively $2462.33 \pm 464.65 \mathrm{~g}$ and $2919.04 \pm 570.62 \mathrm{~g}$, pvalue $=0.0001$ ).

Some differences in selected outcomes emerged when stratifying for the most common cancer site (i.e. breast cancer, thyroid and lymphoma). With regard to PAC diagnosed during pregnancy, elective cesarean section was more common among breast and lymphoma cases than thyroid cases (respectively $82.1 \%$ vs $82.4 \%$ vs $52.9 \%$, $p$ value $=0.048)$, preterm births were more frequent among breast and lymphoma cases compared to thyroid cases (respectively $52.2 \%$ vs $44.4 \%$ vs $17.6 \%$, p-value $=$ 0.037 ) and small for gestational age newborn were more frequent among thyroid cancer and lymphoma, as compared to breast cancer (respectively, 5.1\%, 11.1 and $0 \%$, $p=0.036$ ). No differences emerged between strata of cancer sites among PAC diagnosed after pregnancy (Table 4).

\section{Discussion}

In the current study, PAC diagnosed in pregnancy was associated with an increased risk of labor induction or planned delivery, cesarean section and preterm birth. No associations between PAC and SGA newborns was observed. Nevertheless, PAC were associated to a lower birth weight. Although not significant, newborns of women with PAC diagnosed during pregnancy had a higher risk to obtain a low Apgar score at $5 \mathrm{~min}$. These two adverse neonatal outcomes may be derived by the high incidence of births fewer than 37 weeks; generally premature newborns have a low weight because of their gestational age and they have a tardier adaptation to extra-uterine life after delivery. Therefore, we observed that a diagnosis of PAC had a major impact on the clinical management delivery rather than on the outcomes of newborns. Type and timing of delivery were influenced by the presence of cancer and could lead to consequences on neonatal health.

As previously observed $[8-10,20]$ also in our population elective cesarean section was the preferred mode of delivery among women with $\mathrm{PAC}$, and iatrogenic or induced preterm birth might have been preferred to allow the beginning of cancer treatment. However, awareness is growing that cancer can be treated during pregnancy and the proportion of patients with PAC who receive antenatal treatment increases [21, 22]. Cancer treatment during pregnancy should limit iatrogenic prematurity $[7,23]$.

Our results are generally consistent with previous published data from record linkage studies. In a study from Australia between 1994 and 2008 [9] women with cancer diagnosed during pregnancy had higher rates of labor induction, caesarean section and planned preterm birth with respect to healthy women. The study also reported an association of PAC with multiple pregnancies and large for gestational age (LGA) newborns. Another study carried out in Denmark and Sweden between 1973 and 2008 [20] showed a positive association between PACs and adverse birth outcomes in the offspring (i.e. caesarean section birth, preterm birth, low birth weight, low Apgar score). Recent evidence from Swedish data reported also that maternal cancer during pregnancy was positively associated with an increased risk of fatal outcomes (i.e. stillbirth and infant mortality), mainly among SGA and preterm newborn [24]. 
Table 4 Adverse obstetric and neonatal outcomes stratified by timing of diagnosis and the three most frequent cancer site. Lombardy, Italy. 2008-2017

\begin{tabular}{|c|c|c|c|c|c|c|}
\hline \multirow{2}{*}{ - } & \multicolumn{3}{|c|}{ During Pregnancy Cancers } & \multicolumn{3}{|c|}{ Post-pregnancy Cancer } \\
\hline & $\begin{array}{l}\text { Breast } \\
N=69\end{array}$ & $\begin{array}{l}\text { Thyroid } \\
N=17\end{array}$ & $\begin{array}{l}\text { Lymphoma } \\
N=18\end{array}$ & $\begin{array}{l}\text { Breast } \\
N=190\end{array}$ & $\begin{array}{l}\text { Thyroid } \\
N=121\end{array}$ & $\begin{array}{l}\text { Lymphoma } \\
N=85\end{array}$ \\
\hline \multicolumn{7}{|l|}{ Obstetric outcomes } \\
\hline \multicolumn{7}{|c|}{ Labor induction or planning of delivery ${ }^{b}$} \\
\hline Not Induced & $12(17.9)$ & $8(47.1)$ & $3(17.6)$ & $109(58.0)$ & $66(55.0)$ & $52(61.2)$ \\
\hline \multirow[t]{2}{*}{ Induced or Elective CS } & $55(82.1)$ & $9(52.9)$ & $14(82.4)$ & $79(42.0)$ & $54(45.0)$ & $33(38.8)$ \\
\hline & \multicolumn{3}{|c|}{$p$ value ${ }^{a}=0.048$} & \multicolumn{3}{|c|}{$p$ value $=0.675$} \\
\hline \multicolumn{7}{|l|}{ Mode of Delivery $^{c}$} \\
\hline Vaginal or Instrumental & $31(44.9)$ & $12(70.6)$ & $6(35.3)$ & $129(57.9)$ & $88(72.7)$ & $58(69.1)$ \\
\hline \multirow[t]{2}{*}{ CS } & $38(55.1)$ & $5(29.4)$ & $11(64.7)$ & $61(32.1)$ & $33(27.3)$ & $26(30.9)$ \\
\hline & \multicolumn{3}{|c|}{$p$ value $=0.089$} & \multicolumn{3}{|c|}{$p$ value $=0.659$} \\
\hline \multicolumn{7}{|l|}{ Timing of Birth } \\
\hline At Term & $33(47.8)$ & $14(82.4)$ & $10(55.6)$ & $170(89.5)$ & $111(91.7)$ & 79 (92.9) \\
\hline \multirow[t]{2}{*}{ Preterm } & $36(52.2)$ & $3(17.6)$ & $8(44.4)$ & $20(10.5)$ & $10(8.3)$ & $6(7.1)$ \\
\hline & \multicolumn{3}{|c|}{$p$ value $=0.037$} & \multicolumn{3}{|c|}{$p$ value $=0.607$} \\
\hline \multicolumn{7}{|l|}{ Neonatal outcomes } \\
\hline \multicolumn{7}{|l|}{ SGA } \\
\hline No & $69(100.0)$ & $16(94.1)$ & $16(88.9)$ & $172(90.5)$ & $116(95.9)$ & $74(87.1)$ \\
\hline \multirow[t]{2}{*}{ Yes } & $0(0.0)$ & $1(5.9)$ & $2(11.1)$ & $18(9.5)$ & $5(4.1)$ & $11(12.9)$ \\
\hline & \multicolumn{3}{|c|}{$p$ value ${ }^{a}=0.036$} & \multicolumn{3}{|c|}{$p$ value $=0.071$} \\
\hline \multicolumn{7}{|l|}{ Apgar 5th Minute } \\
\hline Normal & $66(95.6)$ & $17(100.0)$ & $18(100.0)$ & $188(99.0)$ & $120(99.2)$ & $85(100.0)$ \\
\hline \multirow[t]{2}{*}{ Low } & $3(4.4)$ & $0(0.0)$ & $0(0.0)$ & $2(1.0)$ & $1(0.8)$ & $0(0.0)$ \\
\hline & \multicolumn{3}{|c|}{ p value ${ }^{a}=1.000$} & \multicolumn{3}{|c|}{ p value ${ }^{a}=1.000$} \\
\hline \multicolumn{7}{|l|}{ Malformation } \\
\hline No & $69(100.0)$ & $17(100.0)$ & $18(100.0)$ & $190(100.0)$ & $119(98.4)$ & $85(100.0)$ \\
\hline \multirow[t]{2}{*}{ Yes } & $0(0.0)$ & $0(0.0)$ & $0(0.0)$ & $0(0.0)$ & $2(1.6)$ & $0(0.0)$ \\
\hline & & - & & \multicolumn{3}{|c|}{$p$ value ${ }^{a}=0.139$} \\
\hline \multicolumn{7}{|l|}{ Perinatal Mortality } \\
\hline Livebirth & $69(100.0)$ & $17(100.0)$ & $18(100.0)$ & $190(100.0)$ & $120(99.2)$ & $85(100.0)$ \\
\hline \multirow[t]{2}{*}{ Stillbirth } & $0(0.0)$ & $0(0.0)$ & $0(0.0)$ & $0(0.0)$ & $1(0.8)$ & $0(0.0)$ \\
\hline & & - & & & $\mathrm{p}$ value ${ }^{\mathrm{a}}=0$ & \\
\hline
\end{tabular}

CS cesarean section

ausing Fisher's Exact Test

${ }^{b}$ Not including 3 missing data among the non-pregnancy cancer associated women and 3 missing data among the pregnancy cancer associated women

${ }^{\mathrm{c}}$ Not including 1 missing data among the non-pregnancy cancer associated women and 1 missing data among the pregnancy cancer associated women

Only few data are available on the potential differences of the impact on obstetric outcome in women with PAC of different sites. In our study, elective cesarean section was more common among births with a maternal lymphoma than those with a maternal breast or thyroid cancer. Abdominal-pelvic or cervical cancer is a primary indication to cesarean section $[3,23]$. Moreover, the premature births were more common among women with PAC and a high rate of these were iatrogenic or induced deliveries. Spontaneous labor occurred only for the $23.7 \%$ of preterm births among women diagnosed with PAC. In our study, women with thyroid cancer did not follow this pattern, giving birth at term in the most cases.

Medical interventions aimed to anticipating birth due to cancer could cause adverse neonatal outcomes $[8,9,20,24]$. In our study, the higher risks observed among women with PAC during pregnancy for low birth weight and low Apgar score may be driven by the increased frequency of preterm and iatrogenic birth. These findings were consistent with a large 
population-based study conducted in Denmark and Sweden [20].

Some studies reported an increase in the risk of SGA $[20,24]$. Overall, our study did not support this finding, but we observed a higher frequency of SGA following exposure to lymphoma during pregnancy. Studies focusing on PAC and the risk of malformation in newborns generally assessed different potential unfavorable maternal exposures, such as ionizing radiation or chemotherapy [11]. Despite not considering these maternal exposures, in general, we did not observe an increased risk of malformations among PAC cases. Maternal cancer during pregnancy is also associated with an increased risk of fatal outcomes (i.e. stillbirth and infant mortality). This effect may be caused by premature births and SGA [24]. However, in our population the frequency of perinatal mortality was very low, precluding the possibility of comparison between PAC and cancer-free women.

A major strength of this study is its population-based design. HCU databases represent large and validated sources of data that cover patient information over a span of 10 years. HCU databases collect hospitalizations of all Lombardy hospitals and the linkage to CedAP database allowed to assess detailed information about each delivery identified, including a wide range of perinatal outcomes.

Some weaknesses warrant consideration. We defined cancer diagnosis as the first hospital admission due to malignant disease. However, if the first diagnosis was performed at an outpatient setting, hospital data may be less efficient in identifying exact diagnosis timing. Considering all cancer sites overall might be a limitation of our study, as different cancers could have different course and implications on pregnancy outcomes. Moreover, according to our primary aim of assessing the association between PAC and adverse perinatal outcomes, only deliveries (not all pregnancy) were included in the study. The information about the outcomes of interest were collected from CedAP which is filled in only if a delivery is completed.

\section{Conclusions}

In our study, PAC was associated with iatrogenic preterm birth. Consequentially, among PAC women birth weight was lower compared to non PAC women and an increased risk of low Apgar score at 5 min emerged (although non statistically significant). The high incidence of iatrogenic and preterm birth may justify these findings, in fact premature newborns have a lower weight and they obtain a lower Apgar score if compared with at term newborns. In order to guarantee neonatal wellbeing in offspring of women with PAC, careful decisionmaking strategy regarding mode and timing of delivery should be considered. Maternal and fetal health allowing iatrogenic preterm birth should be limited.

\section{Supplementary Information}

The online version contains supplementary material available at https://doi. org/10.1186/s12884-020-03508-4.

\section{Additional file 1.}

Additional file 2

Additional file 3.

\section{Abbreviations}

aPR: Adjusted PrevalenceRatio; ATC: Anatomical Therapeutic Chemical; CeDAP: Certificates of Delivery Assistance; Cl: Confidence Interval; FCS: Fully Conditional Specification; GEE: Generalized Estimating Equations; HCU: HealthCare Utilization; ICD: International Classification of Diseases: IUGR: Intrauterine Growth Restriction; NHS: National Health System; OR: Odds Ratio; PAC: Pregnancy associated cancer; PPROM: Premature Membrane Rupture; PR: Prevalence Ratio; SGA: Small for Gestational Age

\section{Acknowledgements}

Not applicable.

\section{Authors' contributions}

All authors have read and approved the manuscript. GE, MF: methodology, formal analysis, investigation, resources, writing —original draft preparation, visualization, data curation with equal contribution. GS, FP, MD writing-review and editing. CLV, EN, GC: resources writing-review, supervision.

\section{Funding}

This work was supported by a research grant from the Italian Ministry of Education, University and Research ('PRIN' 2017, project 2017728JPK). The grant provides financial support for the analysis of data.

\section{Availability of data and materials}

The data that support the findings of this study are available from Lombardy Region, but restrictions apply to the availability of these data which were used under license for the current study, and so are not publicly available. Data are however available from the authors upon reasonable request and with permission of Lombardy Region.

\section{Ethics approval and consent to participate}

In the Ethics approval section could you please provide a reference that explicitly states that ethics approval is not needed? Alternatively, please indicate if the need for ethical approval has been waived by an IRB.The

Ethical Committee of the University of Milano-Bicocca eval-.

uated the protocol and established that the study (a) was. exempt from informed consent (according to General.

This analysis is exempt from IRB authorization and informed consent (according to General Authorization for the Processing of Personal Data for Scientific Research Purposes issued by the Italian Privacy Authority on December 15, 2016; http://www.garanteprivacy.it/web/guest/ home/ docweb/-/docweb-display/docweb/5805552),

Data and permission for the analysis were obtained by the Regional Health Authorities of Lombardy, Italy.

Consent for publication

Not applicable.

\section{Competing interests}

Giovanni Corrao received research support from the European Community (EC), the Italian Agency of Drugs (AIFA), and the Italian Ministry for University and Research (MIUR). He took part in a variety of projects that were funded by pharmaceutical companies (i.e. Novartis, GSK, Roche, AMGEN and BMS). $\mathrm{He}$ also received honoraria as a member of the advisory board to Roche. The other authors declare that they have no conflicts of interest to disclose. 


\section{Author details}

'National Centre for Healthcare Research and Pharmacoepidemiology, Milan, Italy. ${ }^{2}$ Laboratory of Healthcare Research \& Pharmacoepidemiology, Department of Statistics and Quantitative Methods, University of Milano-Bicocca, Milan, Italy. ${ }^{3}$ Department of Clinical Sciences and Community Health, University of Milan, 20122 Milan, Italy. ${ }^{4}$ Department of Obstetrics, Gynecology and Neonatology, University of Milan, Fondazione IRCCS Ca' Granda Ospedale Maggiore Policlinico, 20122 Milan, Italy.

Received: 10 September 2020 Accepted: 17 December 2020 Published online: 07 January 2021

\section{References}

1. Smith LH, Dalrymple JL, Leiserowitz GS, Danielsen B, Gilbert WM. Obstetrical deliveries associated with maternal malignancy in California, 1992 through 1997. Am J Obstet Gynecol. 2001;184:1504-12.

2. Smith LH, Danielsen B, Allen ME, Cress R. Cancer associated with obstetric delivery: results of linkage with the California cancer registry. Am J Obstet Gynecol. 2003;189:1128-35.

3. Dalrymple JL, Gilbert WM, Leiserowitz GS, Cress R, Xing G, Danielsen B, et al. Pregnancy-associated cervical cancer: obstetric outcomes. J Matern Fetal Neonatal Med. 2005;17:269-76.

4. Andersson TM, Johansson AL, Hsieh CC, Cnattingius S, Lambe M. Increasing incidence of pregnancy-associated breast cancer in Sweden. Obstet Gynecol. 2009;114:568-72.

5. Dahling MT, Xing G, Cress R, Danielsen B, Smith LH. Pregnancy associated colon and rectal cancer: perinatal and cancer outcomes. J Matern Fetal Neonatal Med. 2009;22:204-11.

6. Dalmartello M, Negri E, La Vecchia C, Scarfone G, Buonomo B, Peccatori FA, Parazzini F. Frequency of pregnancy-associated Cancer: a systematic review of population-based studies. Cancers. 2020;12(6):1356.

7. Salani R, Billingsley CC, Crafton SM. Cancer and pregnancy: an overview for obstetricians and gynecologists. Am J Obstetr Gynecol Jul. 2014;211(1):7-14.

8. Van Calsteren K, Heyns L, De Smet F, Van Eycken L, Gziri MM, Van Gemert W, et al. Cancer during pregnancy: an analysis of 215 patients emphasizing the obstetrical and the neonatal outcomes. J Clin Oncol. 2010;28:683-9.

9. Lee $\mathrm{YY}$, Roberts $\mathrm{CL}$, Dobbins $\mathrm{T}$, et al. Incidence and outcomes of pregnancyassociated cancer in Australia, 1994-2008: a population-based linkage study. BJOG. 2012:119:1572-82.

10. Nieminen U, Remes N. Malignancy during pregnancy. Acta Obstet Gynecol Scand. 1970:49(4):315-9.

11. Cardonick E, Eicheldinger E, Gaughan JP. Chemotherapy is avoided during the first trimester of pregnancy, when is the safest time to start treatment during the second or third trimester? ProClinS Gynecology and Obstetrics. 2019;2(1):1005

12. Cantarutti A, Franchi M, Rea F, Merlino L, Corrao G. Use of Nimesulide during early pregnancy and the risk of congenital malformations: a population-based study from Italy. Adv Ther. 2018;35(7):981-92.

13. Lawn JE, Gravett MG, Nunes TM, Rubens CE, Stanton C, GAPPS Review Group. Global report on preterm birth and stillbirth (1 of 7): definitions, description of the burden and opportunities to improve data. BMC Pregnancy Childbirth. 2010;10(Suppl 1):S1.

14. Casey BM, McIntire DD, Leveno KJ. The continuing value of the Apgar score for the assessment of newborn infants. N Engl J Med. 2001;344:467-71.

15. Parazzini F, Cortinovis I, Bortolus R, Zanardo V. Weight at birth between 23a and 42a weeks of gestation in Italy. Med Surg Ped. 1998;20:93-7.

16. Austin PC. An introduction to propensity score methods for reducing the effects of confounding in observational studies. Multivariate Behav Res. 2011:46(3):399-424.

17. Zeger SL, Liang KY. Longitudinal data analysis for discrete and continuous outcomes. Biometrics. 1986:42(1):121-30 PubMed PMID: 3719049.

18. Magnus MC, Stigum H, Håberg SE, Nafstad P, London SJ, Nystad W. Peak weight and height velocity to age 36 months and asthma development: the Norwegian mother and child cohort study. PLoS One. 2015;10(1):e01 16362

19. Verret-Chalifour J, Giquère $Y$, Forest JC, Croteau J, Zhang P, Marc I. Breastfeeding initiation: impact of obesity in a large Canadian perinatal cohort study. PLoS One. 2015;10(2):e0117512.

20. Momen NC, Arendt LH, Ernst A, Olsen J, Li J, Gissler M, Ramlau-Hansen CH. Pregnancy-associated cancers and birth outcomes in children: A Danish and Swedish population-based register study. BMJ Open. 2018;8(12):e022946.
21. Jeremic K, Stefanovic A, Dotlic J, Kadija S, Kontic O, Gojnic M, Jeremic J, Kesic V. Cancer during pregnancy clinical characteristics, treatment outcomes and prognosis for mothers and infants. J Perinat Med. 2018;46(1):35-45.

22. de Hann J, Verheecke M, Van Calsteren K, Van Caalster B, et al. Oncological management and obstetric and neonatal outcomes for women diagnosed with cancer during pregnancy: a 20 year international cohort study of 1170 patients. Lancet Oncol. 2018;19:337-46.

23. Kobayashi Y, Tabata T, Omori M, Kondo E, Hirata T, Yoshida K, Sekine M, Itakura A, Enomoto T, Ikeda T. A Japanese survey of malignant disease in pregnancy. Int J Clin Oncol. 2019;24:328-33.

24. Donghao L, Ludvigsson JF, Smedby KE, Fall K, Valdimarsdottir U, Cnattingius S, Fang F. Maternal cancer during pregnancy and risks of stillbirth and infant mortality. J Clin Oncol. 2017;35:1522-9.

\section{Publisher's Note}

Springer Nature remains neutral with regard to jurisdictional claims in published maps and institutional affiliations.

Ready to submit your research? Choose BMC and benefit from:

- fast, convenient online submission

- thorough peer review by experienced researchers in your field

- rapid publication on acceptance

- support for research data, including large and complex data types

- gold Open Access which fosters wider collaboration and increased citations

- maximum visibility for your research: over $100 \mathrm{M}$ website views per year

At $\mathrm{BMC}$, research is always in progress.

Learn more biomedcentral.com/submissions 